\title{
Morfometria de plantas de girassol ornamental e atributos químicos de um solo irrigado com água residuária e adubado com esterco
}

\section{Ornamental sunflower morphometry and chemical attributes of a soil irrigated with wastewater and fertilized with bovine manure}

\author{
Leandro Oliveira de ANDRADE'; Reginaldo Gomes NOBRE ${ }^{2}$; Nildo da Silva DIAS 3 ; \\ Hans Raj GHEYI ${ }^{4}$; Frederico Antonio Loureiro SOARES ${ }^{5}$; Elka Costa Santos NASCIMENTO6
}

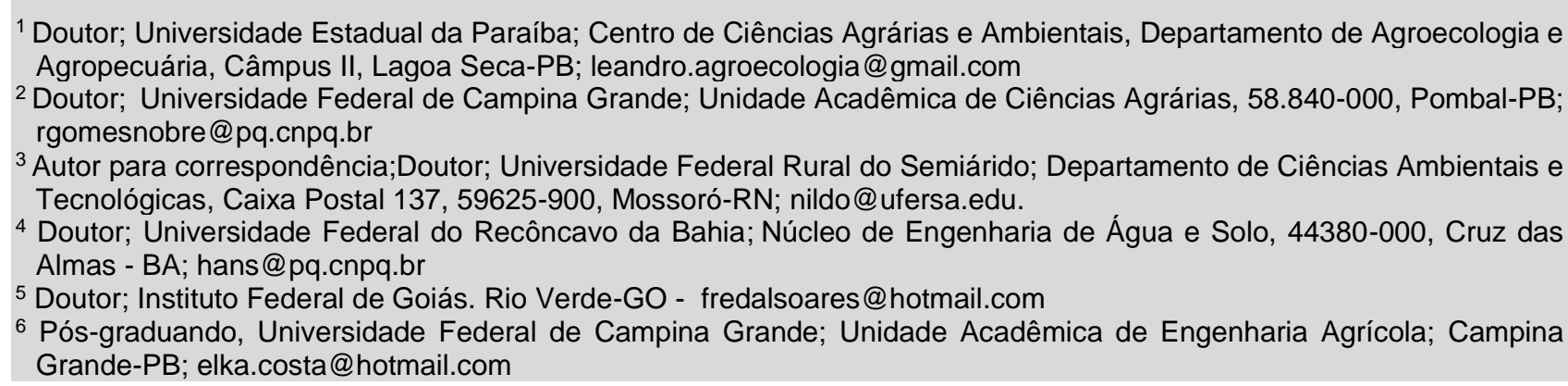

Recebido em: 03-09-2013; Aceito em: 22-02-2015

\section{Resumo}

Neste trabalho, avaliaram-se a morfometria do girassol ornamental e os atributos químicos de um solo irrigado com água residuária e adubado com esterco. O delineamento experimental adotado foi 0 de blocos casualizados em esquema fatorial $4 \times 2$, com 4 repetições e 5 plantas por repetição, sendo 4 doses de esterco bovino curtido $\left(5 ; 10 ; 15\right.$ e $\left.20 \mathrm{dag} \mathrm{kg}^{-1}\right)$, com base em massa, combinado com 2 qualidades de água (água de abastecimento e água residuária tratada oriunda de esgoto doméstico). Avaliaram-se, em 7 épocas de cultivo, as variáveis altura de planta, o diâmetro de caule e, em 5 épocas, a fitomassa seca da parte aérea e da raiz. Após um ciclo cultural, o material de solo contido nos vasos de cultivo foi coletado para caracterização química, determinando-se os íons solúveis $\mathrm{Ca}^{2+}, \mathrm{Mg}^{2+}, \mathrm{K}^{+}, \mathrm{Na}^{+}, \mathrm{Cl}^{-}$e $\mathrm{HCO}_{3}$, além da RAS, pHps e $\mathrm{CE}_{\text {es. Não }}$ houve efeito significativo das distintas qualidades de água sob as variáveis de crescimento estudadas em plantas de girassol. A adubação com dose entre 10 e $15 \mathrm{dag} \mathrm{kg}^{-1}$ de esterco bovino é a mais indicada para se atingir o crescimento máximo do girassol ornamental. Há efeito quadrático crescente nos teores de $\mathrm{Ca}^{2+} \mathrm{e}$ $\mathrm{Mg}^{2+}$ no solo em função das doses de esterco bovino para os solos irrigados com água de abastecimento e efeito linear crescente nos solos irrigados com água residuária. Os teores de $\mathrm{K}^{+} \mathrm{e} \mathrm{Na}^{+}$no solo aumentaram com o incremento das doses de esterco bovino respectivamente, até as doses de 15,06 e 13,74 dag $\mathrm{kg}^{-1} \mathrm{de}^{-}$ esterco bovino, independentemente do tipo de água de irrigação. Para os dois tipos de água de irrigação utilizados, as altas doses de esterco bovino aumentam os riscos de salinização e sodificação do solo e toxicidade às plantas dos íons cloreto.

Palavras-chave adicionais: esgoto doméstico; estrume; Helianthus annuus L.

\begin{abstract}
In this work, we evaluated the morphometry and chemical properties of a soil cropped with ornamental sunflower irrigated with wastewater and fertilized with bovine manure. The experiment was conducted in a randomized block design in a $4 \times 2$ factorial arrangement with four repetitions and five plants per replication. The four doses of bovine manure tested were $5,10,15$, and 20 dag kg-1 on mass basis, combined with two types of water: water from public supply, and wastewater originating from treated domestic sewage. On seven cropping dates the variables plant height, stem diameter, and on five dates, the aerial and root parts dry mass were evaluated. At the end of crop cycle, the soil of the pots was collected and chemically characterized by the determination of the soluble ions $\mathrm{Ca}^{2+}, \mathrm{K}^{+}, \mathrm{Na}^{+}, \mathrm{Cl}^{-}$, and $\mathrm{HCO}_{3}^{-}$, in addition to the $\mathrm{SAR}, \mathrm{pH}_{\mathrm{ps}}$, and ECse. Water quality had no effect on the evaluated characteristics. The fertilization with dose between 10 and 15 dag $\mathrm{kg}^{-1}$ of bovine manure is the most appropriate to achieve maximum growth of ornamental sunflower. There is a crescent quadratic effect on the $\mathrm{Ca}^{2+}$ and $\mathrm{Mg}^{2+}$ content in the soil as a result of increasing doses of bovine manure. $\mathrm{K}^{+}$and $\mathrm{Na}^{+}$content in the soil increase with increasing doses of bovine manure up to 15.06 and 13.74 dag $\mathrm{kg}^{-1}$, respectively, independently of the type of irrigation water. For both types of irrigation water, high doses of bovine manure increase the risks of soil salinization and sodification and toxicity of chloride ions to plants.
\end{abstract}

Additional keywords: cattle manure; Helianthus annuus L; sewage. 


\section{Introdução}

O homem utiliza a água para diversas atividades, e sua escassez é um fator limitante ao desenvolvimento econômico e social de uma região, e a multiplicidade de seu uso pode gerar competição e conflitos (Duarte et al., 2008).

O uso de esgoto doméstico tratado para irrigação é uma prática antiga e popular na agricultura; entretanto, no Brasil, essa prática ainda é recente. Embora, o reúso de água possa mitigar os danos causados pela utilização elevada de recursos hídricos naturais e utilizar a diversidade nutricional dos corpos de água, nesta prática devem-se considerar, também, os riscos de contaminação ambiental que pode causar aos solos cultivados (Fonseca et al., 2005).

Os efeitos da aplicação de água residuária nas alterações dos atributos químicos e físicos do solo só são pronunciados após longo período de aplicação, pelos atributos que definem sua composição física e química, pelas condições de clima e pelo tipo de solo (Rodrigues et al., 2009). Ayers \& Westcot (1999) relatam que a limitação principal do uso de águas residuárias na agricultura é sua composição química (totais de sais dissolvidos, presença de íons tóxicos e concentração relativa de sódio) e a sensibilidade das culturas a esse tipo de efluente.

Porém, quando se utiliza efluente de esgoto doméstico como fonte hídrica e nutricional na agricultura, quase sempre, a carga nutricional disponível não é suficiente para atender à demanda da cultura explorada e, geralmente, há necessidade de complementação de adubação para garantir a boa produtividade. Neste caso, recomenda-se a utilização de adubos orgânicos, de vez que enseja melhoria na fertilidade e na conservação do solo (Galvão et al., 2008) com menor risco de degradação do solo. Além disso, o uso de adubos orgânicos, como, por exemplo, o esterco bovino, melhora a estrutura física, retém a umidade e aumenta o teor de matéria orgânica, especialmente nos solos do semiárido e no agreste do Nordeste do Brasil, que, em geral, são pobres em matéria orgânica e, por consequência, a produtividade, sem adubação, é muito baixa (Menezes \& Salcedo, 2007).

Do ponto de vista dos riscos de contaminação ambiental, o reúso de água exige uma gestão mais complexa da prática de irrigação e um monitoramento mais restrito dos procedimentos em comparação com água de melhor qualidade que geralmente é usada.

Levando-se em consideração estes aspectos, o objetivo deste estudo foi avaliar a morfometria do girassol ornamental e a qualidade química de solo, após irrigação com água residuária associada à adubação orgânica (esterco bovino).

\section{Material e métodos}

O experimento foi conduzido no período de 10 de setembro a 1o de dezembro de 2010 , em casa de vegetação do tipo capela, pertencente à Unidade Acadêmica de Engenharia Agrícola (UAEAg), da Universidade Federal de Campina Grande - UFCG, cujas coordenadas geográficas são 7015'18" de latitude sul, $35^{\circ} 52^{\prime} 28^{\prime \prime}$ de longitude oeste e altitude de $550 \mathrm{~m}$. O clima da região, conforme a classificação climática de Köppen, é do tipo As, que representa clima de Savana, tropical, com chuvas de inverno, e verão seco. O município de Campina Grande apresenta precipitação total anual de $802,7 \mathrm{~mm}$, temperatura máxima de $27,5^{\circ} \mathrm{C}$, mínima de $19,2{ }^{\circ} \mathrm{C}$ e umidade relativa do ar de $83 \%$ (Alves et al., 2009).

Utilizaram-se sementes de girassol (Helianthus annuus L., variedade Sol Noturno), desenvolvida pela empresa ISLA Sementes e, para a propagação, adotouse a recomendação da empresa relativa à profundidade de semeadura de $3 \mathrm{~cm}$, diretamente feito no local de cultivo até a data do desbaste, avaliações destrutivas ou colheita.

O delineamento experimental adotado foi o em blocos casualizados, em esquema fatorial $2 \times 4$, com 4 repetições, tendo 5 plantas por repetição. As plântulas de girassol foram irrigadas com água de abastecimento e água residuária tratada desde sua germinação (Tabela 1), e o material de solo adubado com quatro doses de esterco bovino curtido (5; 10; 15 e 20 dag $\mathrm{kg}^{-1} \mathrm{com}$ base na massa total de $8 \mathrm{~kg}$ de solo como suporte máximo do vaso em uso). O esterco bovino apresentou, em média, 62, 0,5, 0,2 e 0,4 dag $\mathrm{kg}^{-1}$ de matéria orgânica, $\mathrm{N}, \mathrm{P}_{2} \mathrm{O}_{5}$ e $\mathrm{K}_{2} \mathrm{O}$, respectivamente.

Cada unidade experimental foi composta de um vaso de plástico de $10 \mathrm{~L}$ preenchido com solo, sob o qual havia um sistema drenante constituído por uma camada de pedra brita no 5 que era separada do solo por manta geotêxtil porosa. O solo adicionado aos vasos era originado de um Neossolo Regolítico distrófico tipo franco-arenoso, não salino e não sódico, coletado na camada superficial $(0-20 \mathrm{~cm})$ em uma área localizada no município de Campina Grande-PB, distrito de São José da Mata. Esse material foi destorroado, homogeneizado, passado em peneira com malha de $5 \mathrm{~mm}$ e seco ao ar; após o que foi caracterizado quimicamente (Tabela 2) no Laboratório de Irrigação e Salinidade, da Universidade Federal de Campina Grande de acordo com as metodologias recomendadas pela Embrapa (1997).

O preenchimento dos vasos com o material de solo e esterco foi realizado conforme as doses estudadas, de forma que essas doses se localizassem no primeiro terço do vaso, facilitando a absorção dos nutrientes pelas raízes das plantas. Um vaso de cada tratamento com planta foi utilizado como lisímetro de drenagem a fim de estimar o volume de água a ser aplicada na irrigação, ou seja, drenaram no início até que o solo contido no vaso pudesse atingir a capacidade de vaso ("capacidade de campo" para as condições do solo acondicionado no vaso), no dia anterior ao da semeadura. 
Tabela 1 - Análises químicas das águas do experimento. Chemical analyses of the waters used in the experiment.

\begin{tabular}{|c|c|c|c|c|c|c|c|c|c|c|c|c|c|}
\hline \multirow{2}{*}{ Mês } & \multirow{2}{*}{$\mathrm{pH}$} & CE & $P_{\text {total }}$ & $\mathrm{K}$ & $\mathrm{N}$-total & $\mathrm{Na}$ & $\mathrm{Ca}$ & $\mathrm{Mg}$ & $\mathrm{Zn}$ & $\mathrm{Cu}$ & $\mathrm{Fe}$ & $\mathrm{Mn}$ & \multirow{2}{*}{ (1) RAS } \\
\hline & & $\left(d S m^{-1}\right)$ & \multicolumn{10}{|c|}{$\begin{array}{l}--1 \\
\end{array}$} & \\
\hline \multicolumn{14}{|c|}{ Água de abastecimento } \\
\hline Média & 7,1 & 0,32 & ${ }^{*} \mathrm{~A}$ & 5,43 & A & 35,6 & 22 & 15,6 & ${ }^{\star} \mathrm{A}$ & ${ }^{*} \mathrm{~A}$ & ${ }^{*} \mathrm{~A}$ & ${ }^{*} \mathrm{~A}$ & 1,44 \\
\hline \multicolumn{14}{|c|}{ Água residuária tratada } \\
\hline Setembro & 7,9 & 1,06 & 3,59 & 30,4 & 28,7 & 172,2 & 50,3 & 44,5 & 0,01 & 0,009 & 0,001 & 0,003 & 4,53 \\
\hline Outt & 7,8 & 1,10 & 3,69 & 30,4 & 29,4 & 171,5 & 51,4 & 48,0 & 0,01 & 0,004 & 0,001 & 0,001 & 4,16 \\
\hline Novembro & 8,1 & 1,40 & 3,71 & 30,5 & 32,9 & 179,6 & 54,4 & 48,2 & 0,01 & 0,004 & 0,001 & 0,011 & 4,28 \\
\hline Média & 7,9 & 1,19 & 3,66 & 30,4 & 30,3 & 174,4 & 52,0 & 48,1 & 0,01 & 0,006 & 0,001 & 0,005 & 4,32 \\
\hline
\end{tabular}

${ }^{(1)}$ unidade - $\left(\mathrm{mmol} \mathrm{L}^{-1}\right)^{0,5} ;{ }^{*} \mathrm{~A}$ - ausente.

O volume de água aplicado em cada irrigação foi calculado com base no balanço de água (volume aplicado - volume drenado) nos lisímetros de cada um dos tratamentos, que foram posicionados ao centro da casa de vegetação.

A irrigação foi iniciada aos 7 dias após a semeadura (DAS), com turno de rega de 2 dias, seguindo a ordem dos tratamentos. A cada irrigação, foram feitas as avaliações de $\mathrm{pH}$ e de condutividade elétrica (CE) das águas de abastecimento e residuária e, mensalmente, a análise química das mesmas com base na amostra coletada em cada irrigação (Tabela 1).
Todos os tratamentos estudados (adubação e tipos de água) foram iniciados antes da semeadura para que, durante todo o período da pesquisa, fossem avaliadas as variáveis de emergência, crescimento e desenvolvimento, sob o efeito dos mesmos. Além das avaliações de $\mathrm{CE}$ e pH das amostras mensais de cada tipo de água, foram feitas análises químicas no Laboratório de Irrigação e Salinidade da Universidade Federal de Campina Grande, seguindo-se as metodologias propostas pela Embrapa (1997) (Tabela 1).

Tabela 2 - Características químicas do Neossolo Regolítico distrófico utilizado no experimento. Chemical characteristics of the dystrophic Rigolitic Neo soil used in the experiment.

\begin{tabular}{|c|c|c|c|c|c|c|c|c|c|c|c|c|c|}
\hline \multicolumn{4}{|c|}{ Complexo sortivo } & \multicolumn{8}{|c|}{ Extrato de saturação } & \multirow[b]{2}{*}{${ }^{*} \mathrm{pH}$ ps } & \multirow{3}{*}{$\begin{array}{l}{ }^{* *} \mathrm{CE}_{\text {es }} \\
\left(\mathrm{dS} \mathrm{m}^{-1}\right)\end{array}$} \\
\hline $\mathrm{Ca}^{2+}$ & $\mathrm{Mg}^{2+}$ & $\mathrm{Na}^{+}$ & $\mathrm{K}^{+}$ & $\mathrm{Cl}^{-}$ & $\mathrm{CO}_{3}{ }^{2-}$ & $\mathrm{HCO}_{3}^{-}$ & $\mathrm{SO}_{4}{ }^{2-}$ & $\mathrm{Ca}^{2+}$ & $\mathrm{Mg}^{2+}$ & $\mathrm{Na}^{+}$ & $\mathrm{K}^{+}$ & & \\
\hline--- & $-(\mathrm{cm}$ & $\left.\mathrm{rg}^{-1}\right)-$ & --- & -- & - & ----- & $(\mathrm{mmol}$ & $\left.L^{-1}\right)--$ & - & & -- & & \\
\hline 1,87 & 1,05 & 0,06 & 0,23 & 3,75 & - & 1,70 & - & 1,75 & 2,00 & 1,12 & 0,55 & 6,15 & 0,67 \\
\hline
\end{tabular}

${ }^{*} \mathrm{pH}_{\mathrm{ps}}-\mathrm{pH}$ da pasta saturada, ${ }^{\star *} \mathrm{CEES}_{\mathrm{ES}}$ - Condutividade elétrica do extrato de saturação

A água residuária tratada, utilizada na irrigação do experimento, proveio do córrego de Monte Santo, esgoto doméstico que cruza a área experimental, oriunda dos bairros Monte Santo e Bodocongó, localizados próximo ao perímetro do Câmpus da UFCG. A água foi captada por meio de bomba SAP e tratada, primeiramente, por sistema de wetland, lagoa de estabilização e, como segundo tratamento, passou por Reator Anaeróbio de Manta de Lodo (Upflow Anaerobic Sludge Blanket - UASB). A fase final deste processo ocorreu quando a água foi descarregada pela parte superior do reator de onde caiu em um reservatório de $5000 \mathrm{~L}$ de capacidade e, em seguida, foi bombeada para o reservatório de $200 \mathrm{~L}$, na casa de vegetação, diretamente de onde era utilizada na irrigação.

Foram semeadas 3 sementes por vaso e, posteriormente, feito 0 desbaste das plântulas, deixando-se uma planta por vaso, segundo o critério de vigor baseado na altura de planta e coloração das folhas, a partir do primeiro dia de avaliação destrutiva para análise de variável de crescimento, aos 20 DAS.

Apesar de as plantas da variedade serem multicapituladas, algumas apresentavam ainda a produção de único capítulo floral, devido a uma variação genética das sementes, porém foram manejadas visando somente ao capítulo central ou apical e, para a obtenção desta única flor no caule, foi praticado o "pinch" ou beliscão, retirando-se assim os botões, axilares ou laterais, visando a evitar o gasto de energia da planta.

As variáveis de crescimento foram analisadas em 7 épocas de coleta, a partir do 20ㅇ DAS até a data de colheita individual das flores cortadas, que variou conforme os tratamentos, ou seja, aos $20 ; 27 ; 34 ; 41$; 48 e 55 DAS, e na ocasião individual da colheita (em média 62 DAS), sendo medidos a altura de planta, tomando-se como base inferior o nível do solo e como limite vertical superior o meristema apical na planta avaliada, e o diâmetro de caule, com medição feita com paquímetro digital a $3 \mathrm{~cm}$ de altura, considerando-se como base a superfície do solo.

Além disso, avaliaram-se a produção de massa seca aos 23; 30; 37 e 44 DAS e na ocasião da colheita, quais sejam: fitomassa seca de folhas (FSF), de caule (FSC), de flor (FSFlor), da parte aérea (FSPA), de raiz (FSR) e total (FST) por planta. Para a obtenção da fitomassa seca, inicialmente, realizou-se o corte da 
planta rente ao solo e alocou-se o material separadamente (folhas, caule, flor e raízes) em saco de papel, colocando-os, em seguida, em estufa com temperatura constante de $62^{\circ} \mathrm{C}$, durante o período de $72 \mathrm{~h}$, até se obter peso constante. A fitomassa seca da parte aérea foi composta pelo peso seco do material de folha e caule. Já as raízes foram separadas do solo, com auxílio de peneira de malha fina e lavagem com água destilada, não descartando nenhuma porção das raízes, e posteriormente conduziu-se a estudo.

Fizeram-se ainda as análises químicas de salinidade das parcelas, ou seja, após o término do experimento (final do ciclo do girassol), no Laboratório de Irrigação e Salinidade, pertencente à UFCG, de acordo com o manual de análise de solo (Embrapa, 1997).

As variáveis $\mathrm{Ca}^{2+}, \mathrm{Mg}^{2+}, \mathrm{K}^{+}, \mathrm{Na}^{+}, \mathrm{Cl}^{-}, \mathrm{HCO}_{3}^{-}$ solúveis, $\mathrm{pH}_{\mathrm{ps}}$ e $\mathrm{CE}$ do extrato de saturação ( $\mathrm{CE}_{\mathrm{es}}$ ) e a RAS foram avaliados de forma individual, ao final do período experimental.

As variáveis de crescimento e os atributos químicos do solo, nos diferentes tratamentos, foram avaliados mediante análise de variância (teste $\mathrm{F}$ ), sendo as médias do fator tipo de água comparadas pelo teste de Tukey, a 0,01 de probabilidade, após transformações das variáveis $\mathrm{Ca}^{2+}, \mathrm{Mg}^{2+}, \mathrm{K}^{+}, \mathrm{Na}^{+}$e $\mathrm{Cl}^{-}$

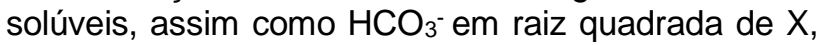
com o $\mathrm{pH}_{\mathrm{ps}}, \mathrm{CE}_{\mathrm{es}} \mathrm{e}$ a RAS, mantendo-se sem transformação.

\section{Resultados e discussão}

\section{- Crescimento de girassol}

De acordo com a análise de variância, houve efeitos significativos sobre a altura de planta (AP) de girassol para os fatores tipo de água de irrigação, aos 48 e 55 DAS $(p<0,05)$, doses de esterco para todas as épocas de avaliação $(p<0,01)$ e da interação tipo de água $x$ doses de esterco aos 27; 34 e 41 DAS.

Pode-se verificar, na Tabela 3, que aos 48 e 55 DAS, a altura das plantas de girassol irrigado com água residuária foram superiores à água de abastecimento; nas demais épocas de avaliação, não houve diferença significativa. No trabalho desenvolvido por Souza et al. (2010), em que foram testados os efeitos de doses de húmus e tipo de água sobre o girassol ornamental BRS OÁSIS, foram registrados incrementos significativos na altura de plantas com o uso da água residuária, desde a primeira época de avaliação até a colheita.

Tabela 3 - Valores médios de altura de planta e diâmetro de caule aos 20; 27; 34; $41 ; 48$ e 55 dias após a semeadura (DAS) e na ocasião da colheita, em plantas de girassol ornamental (cv. Sol Noturno) irrigado com água de abastecimento e residuária. Mean plant height and stem diameter at 20, 27, 34, 41, 48, and 55 days after sowing (DAS) and at harvest time of sunflower plants (cv. 'Sol Noturno') irrigated with supply water and wastewater.

\begin{tabular}{lrrrrrrr}
\hline \multirow{2}{*}{ Tipo de água } & \multicolumn{7}{c}{ Épocas de avaliações - DAS } \\
\cline { 2 - 8 } & 20 & 27 & 34 & 41 & 48 & 55 & Colheita \\
\hline & & \multicolumn{7}{c}{ Altura de plantas $(\mathrm{cm})$} \\
Abastecimento & $6,50 \mathrm{a}$ & $13,32 \mathrm{a}$ & $24,69 \mathrm{a}$ & $40,00 \mathrm{a}$ & $57,63 \mathrm{a}$ & $76,94 \mathrm{a}$ & $95,63 \mathrm{a}$ \\
Residuária & $8,88 \mathrm{a}$ & $16,19 \mathrm{a}$ & $29,00 \mathrm{a}$ & $44,19 \mathrm{a}$ & $68,32 \mathrm{~b}$ & $89,00 \mathrm{~b}$ & $109,31 \mathrm{a}$ \\
\hline & \multicolumn{7}{c}{ Diâmetro do caule $(\mathrm{cm})$} \\
Abastecimento & $2,56 \mathrm{a}$ & $4,13 \mathrm{a}$ & $6,38 \mathrm{a}$ & $7,69 \mathrm{a}$ & $9,00 \mathrm{a}$ & $10,13 \mathrm{a}$ & $10,56 \mathrm{a}$ \\
Residuária & $2,94 \mathrm{a}$ & $4,63 \mathrm{a}$ & $5,75 \mathrm{a}$ & $7,50 \mathrm{a}$ & $9,56 \mathrm{a}$ & $10,38 \mathrm{a}$ & $11,06 \mathrm{a}$ \\
\hline
\end{tabular}

Com relação à interação entre os fatores tipo de água $x$ doses de esterco, observou-se efeito significativo aos 27; 34 e 41 DAS; certamente, o tratamento de dose de esterco foi o fator que mais influenciou nesta interação, posto que o tipo de água (A) não refletiu em diferenças significativas nessas datas, e a adoção das doses de esterco de bovino proporcionou comportamento crescente de AP durante todo o ciclo $(p<0,01)$.

Nota-se que, em todas as épocas de coleta, as menores médias de AP foram estimadas segundo equações de regressão, na dose de $20 \mathrm{dag} \mathrm{kg}^{-1}$ de esterco (Figura 1A). As menores alturas neste tratamento podem ser uma consequência do elevado teor de sais presente no esterco bovino. Por outro lado, as doses de 10 e $15 \mathrm{dag} \mathrm{kg}^{-1}$ foram as que proporcionaram maior crescimento.
Aos 20 DAS, a dose de 20 dag $\mathrm{kg}^{-1}$ apresentou AP igual a $3,91 \mathrm{~cm}$, enquanto que nos tratamentos de 5,10 e 15 dag $\mathrm{kg}^{-1}$ observou-se altura, respectivamente, 39,96, 138,54 e $48,62 \%$ superior; para os mesmos tratamentos na colheita, aos 62 DAS às diferenças foram de 4,63, 35,71 e $37,28 \%$, sendo as plantas sob tratamento de 20 dag $\mathrm{kg}^{-1}$ apresentando altura média de $87,29 \mathrm{~cm}$ (Fig. 1A). Esses resultados indicam que a melhor dose de esterco bovino para cultivo de girassol, em vasos, situa-se entre 10 e $15 \mathrm{dag} \mathrm{kg}^{-1}$.

Houve efeito significativo $(p<0,01)$ das doses de esterco em todas as épocas de avaliação para variável diâmetro do caule (DC); entretanto, não se observou efeito significativo $(p>0,05)$ do fator tipo de água de irrigação e, ainda, da interação tipo de água $x$ doses de esterco, exceto para a interação aos 20 DAS. 

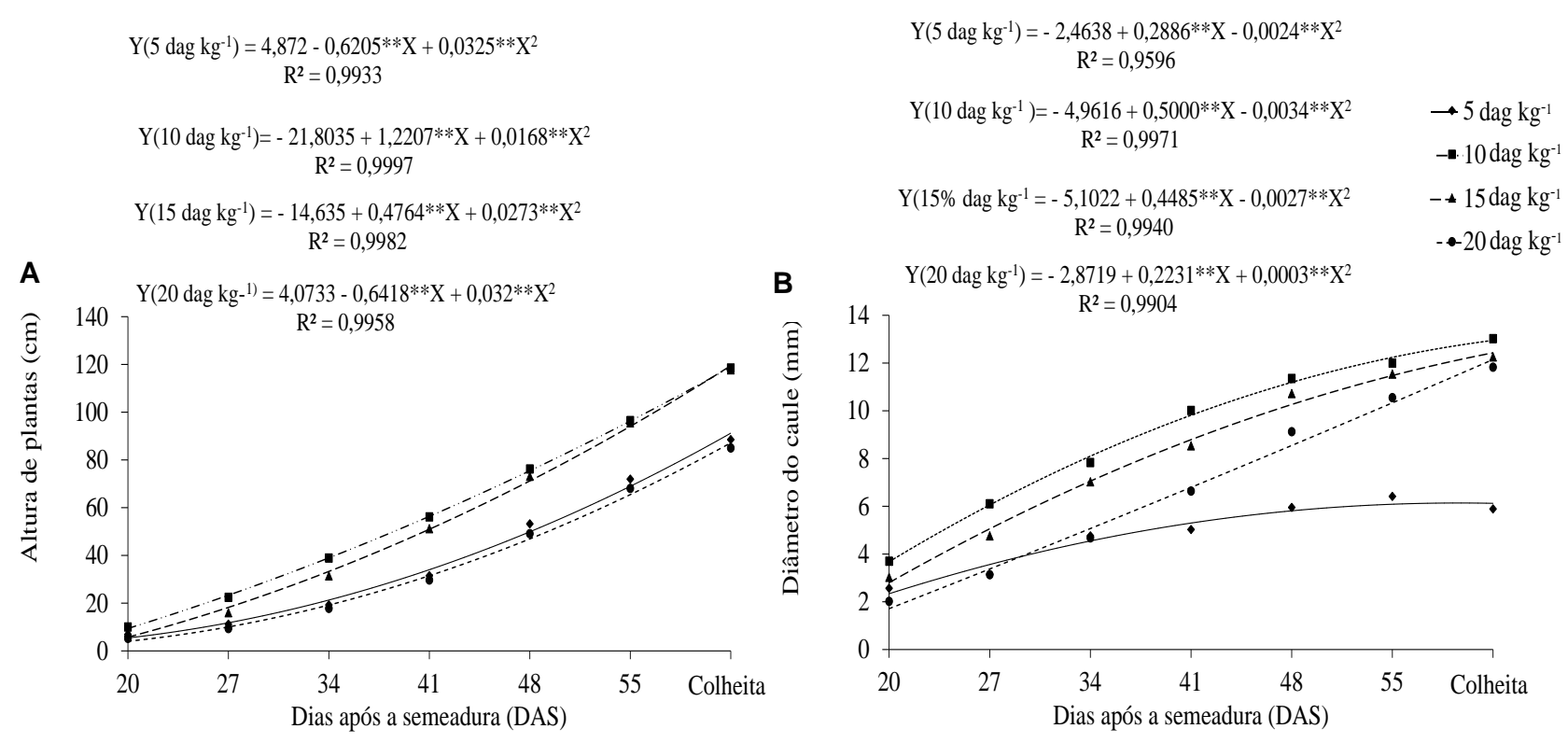

Figura 1 - Altura de plantas (A) e diâmetro de caule (B) do girassol ornamental (cv. Sol Noturno), em função dos dias após a semeadura, sob diferentes doses de esterco bovino. Plant height $(A)$ and stem diameter $(B)$ of the ornamental sunflower (cv. 'Sol Noturno') as influenced by the number of days after sowing under different doses of bovine manure.

Pode-se verificar que não há diferença significativa do DC das plantas do girassol irrigado com água residuária e de abastecimento em todas as épocas de avaliação, conforme comparação de médias.

A interação doses de esterco $x$ tipo de água $(D \times A)$ significativa $(p<0,01)$ ocorrida na primeira data de avaliação deu-se devido às doses de esterco, posto que não houve significância para o fator água em nenhuma época de avaliação.

Estima-se pelas equações de regressão que os maiores valores de DC foram observados na dose de $10 \mathrm{dag}^{\mathrm{kg}}{ }^{-1}$ de esterco em todas as épocas enquanto os menores foram observados sob a aplicação de $5 \mathrm{dag} \mathrm{kg}^{-1}$ exceto aos 20 e 27 DAS onde as plantas com dose de 20 dag kg-1 $^{-1}$ apresentaram medias inferiores (Figure $1 \mathrm{~B}$ ).

Constata-se que aos 20 DAS os tratamentos nas doses de 5,10 e $15 \mathrm{dag} \mathrm{kg}^{-1}$ apresentaram DC $37,42,115,10$ e $62,56 \%$ superior, em relação a dose de $20 \mathrm{dag} \mathrm{kg}^{-1}(1,71 \mathrm{~mm})$. Por outro lado, aos $62 \mathrm{DAS}$, na colheita, as plantas sob doses de 10, 15 e 20 dag $\mathrm{kg}^{-1}$ foram com valores de DC, respectivamente, 109,10, 98,82 e 95,21\% maiores em relação às sob dose de 5 dag $\mathrm{kg}^{-1}$ que tiver DC igual a $6,20 \mathrm{~mm}$. Esses resultados revelam que a incorporação de $10 \mathrm{dag} \mathrm{kg}^{-1}$ de esterco bovino proporcionou melhores resultados. Vale salientar que para AP também esse tratamento tinha sido um dos melhores.

Em plantas de milho, Costa et al. (2009) verificaram, em todas as datas de avaliação, incrementos em DC devido à aplicação de água residuária, assim como Souza et al. (2010) para o girassol e Sampaio et al. (2011) para mudas de meloeiro 'Amarelo Ouro', todos apresentando resultados discordantes com o presente estudo.
De acordo com a análise de variância, observou-se que houve efeito significativo $(p<0,01)$ na variável fitomassa seca da parte aérea do girassol em todas as épocas de avaliação apenas para o fator dose de esterco, sendo observado o efeito quadrático das doses de esterco para esta variável (Figura 2), registrando-se aos 23; 30; 37 e 44 DAS doses ótimas de esterco iguais a 10,89; 11,96; 12,12 e 12,72 dag kg-1 $^{-1}$, respectivamente.

Com relação à variável fitomassa seca de raiz, houve efeito significativo $(p<0,01)$ do fator dose de esterco apenas aos 37 e 44 DAS, não sendo verificado efeito $(p>0,01)$ do fator tipo de água e nem da interação tipo de água $x$ dose de esterco para nenhuma data de estudo. As médias de fitomassa seca da raiz produzida aos 23 e 30 DAS foram de 3,28 e $3,65 \mathrm{~g}$, respectivamente. Porém, aos 37 e 44 DAS, ocorreu efeito quadrático crescente das doses de esterco sobre a produção de fitomassa, registrando-se doses ótimas de esterco iguais a 12,12 e 12,58 dag kg-1 , respectivamente (Figura 3).

De igual forma à fitomassa seca da parte aérea e raiz, houve efeito significativo $(p<0,01)$ apenas do fator doses de esterco para as variáveis fitomassa seca da folha, caule, flor, parte aérea e total de raiz na ocasião da colheita. Observam-se respostas quadráticas crescentes das doses de esterco sobre a produção de fitomassa seca em todas as partes das plantas de girassol na época da colheita (Figura 4).

Com relação às doses de esterco que produz maior quantidade de fitomassa das folhas, caule, flor, raiz, parte aérea e total do girassol, registraram-se valores de 15,$05 ; 15,02 ; 15,45 ; 13,94 ; 15,08$ e 14,81 dag $\mathrm{kg}^{-1}$, respectivamente, ficando evidente que, entre 
as partes das plantas, a raiz é a que necessita de menor quantidade de nutrientes (nitrogênio) para atingir a produção máxima de fitomassa seca.

Apesar de o $\mathrm{N}$ estar disponível na água residuária utilizada na irrigação, as plantas deste experimento não mostraram tais incrementos, provavelmente por que a concentração do elemento não era suficiente para conversão em crescimento significativo. Além disso, deve-se ressaltar que, no presente estudo, o uso da água residuária foi combinado com doses de esterco (mínimo de 5 dag $\mathrm{kg}^{-1}$ ) o que, provavelmente, anulou o efeito positivo da água residuária sob o crescimento das plantas.

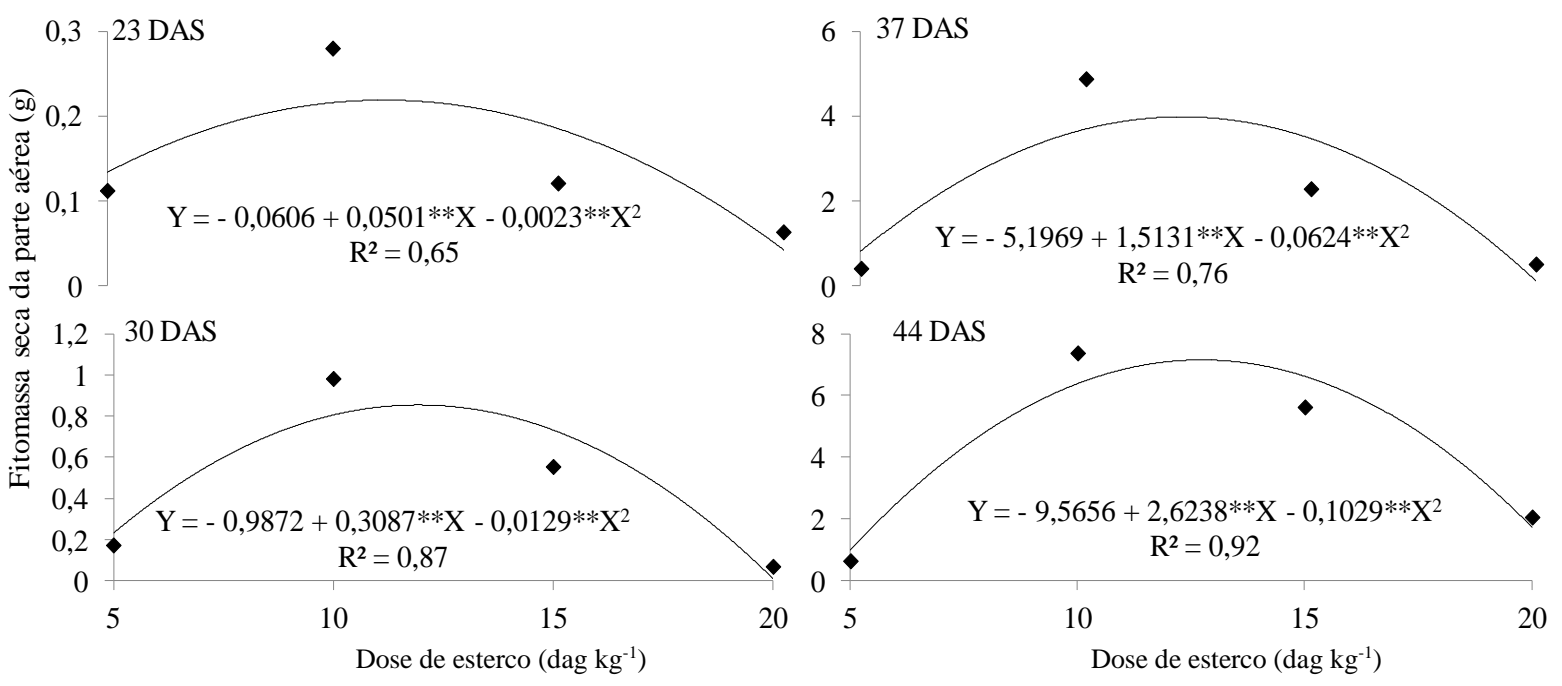

Figura 2 - Fitomassa seca da parte aérea de plantas de girassol ornamental (cv. 'Sol Noturno') aos 23; 30 ; 37 e 44 dias após a semeadura (DAS), em função das doses de esterco. Dry mass of the aerial parts of ornamental sunflower (cv. 'Sol Noturno') plants 23, 30, 37, and 44 days after sowing as influenced by bovine manure doses.

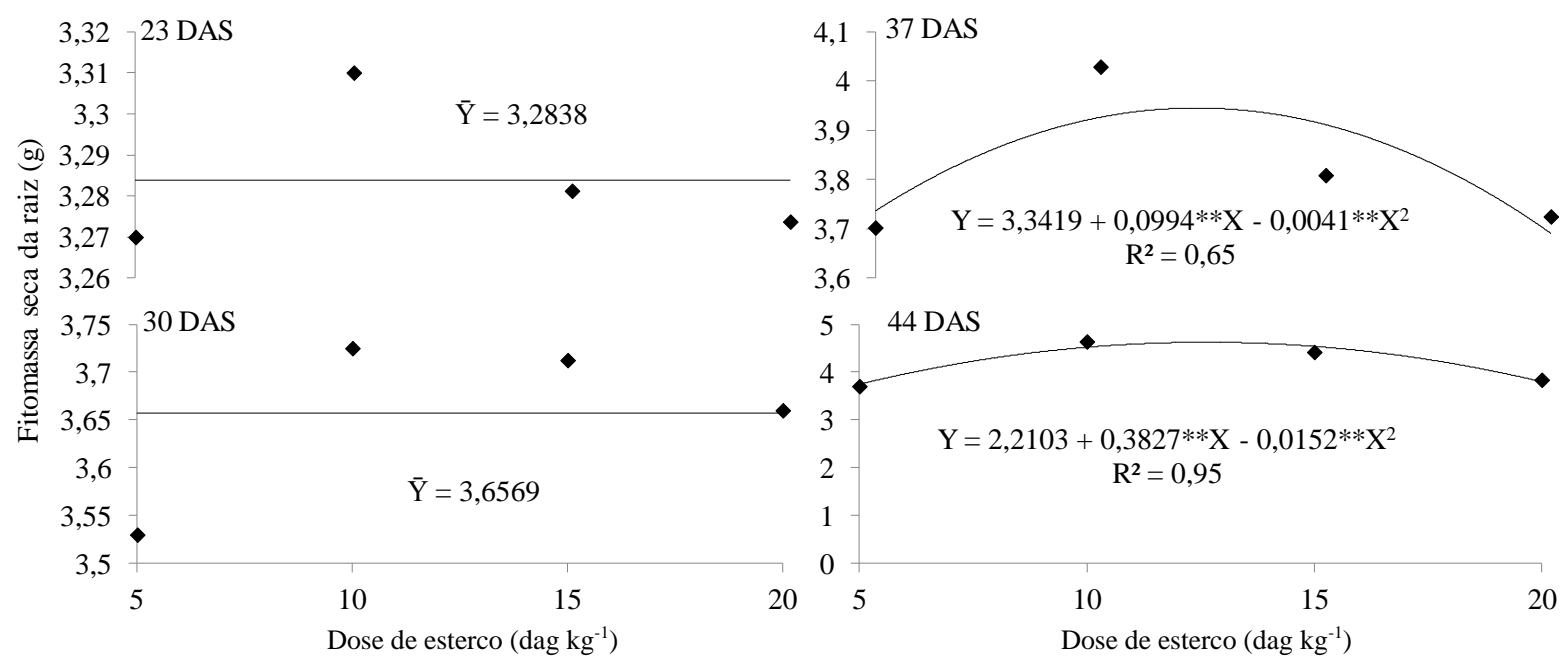

Figura 3 - Fitomassa seca da raiz de plantas de girassol ornamental (cv. 'Sol Noturno') aos 23, 30, 37 e 44 dias após semeadura (DAS), em função das doses de esterco. Dry mass of the roots of ornamental sunflower (cv. 'Sol Noturno') plants 23, 30, 37, and 44 days after sowing as influenced by bovine manure doses.

- Qualidade química do solo

O teor de cálcio $\left(\mathrm{Ca}^{+2}\right)$ na água residuária é superior ao da água de abastecimento em 2,37 vezes (Tabela 2); porém, após a irrigação por um ciclo cultural do girassol, observou-se que o teor de cálcio foi superior nos solos irrigados com água de abastecimento quando comparado aos irrigados com água residuária (Tabela 4).

Houve efeito quadrático significativo no teor de
$\mathrm{Ca}^{2+}$ no solo em função das doses de esterco bovino aplicado nos solos irrigados com água de abastecimento, sendo que o teor de $\mathrm{Ca}^{2+}$ aumentou com o incremento das doses de esterco até a dose de 13,05 dag $\mathrm{kg}^{-1}$ (ponto de máximo) e reduziu acima desta dose. Já para a irrigação com água residuária, o efeito foi linear, em que se observa um acréscimo de 0,338 $\mathrm{mmol}_{\mathrm{c}} \mathrm{L}^{-1}$ de $\mathrm{Ca}^{2+}$ para cada incremento unitário da dose de esterco, demostrando que a aplicação de 
água residuária tem tendência a aumentar o teor de $\mathrm{Ca}^{2+}$ ao longo do tempo (Figura 5A). Na dose de 15 dag $\mathrm{kg}^{-1}$ de esterco, o teor estimado de $\mathrm{Ca}^{2+}$ no solo irrigado com água de abastecimento foi 2,34 vezes maior em relação à água residuária.
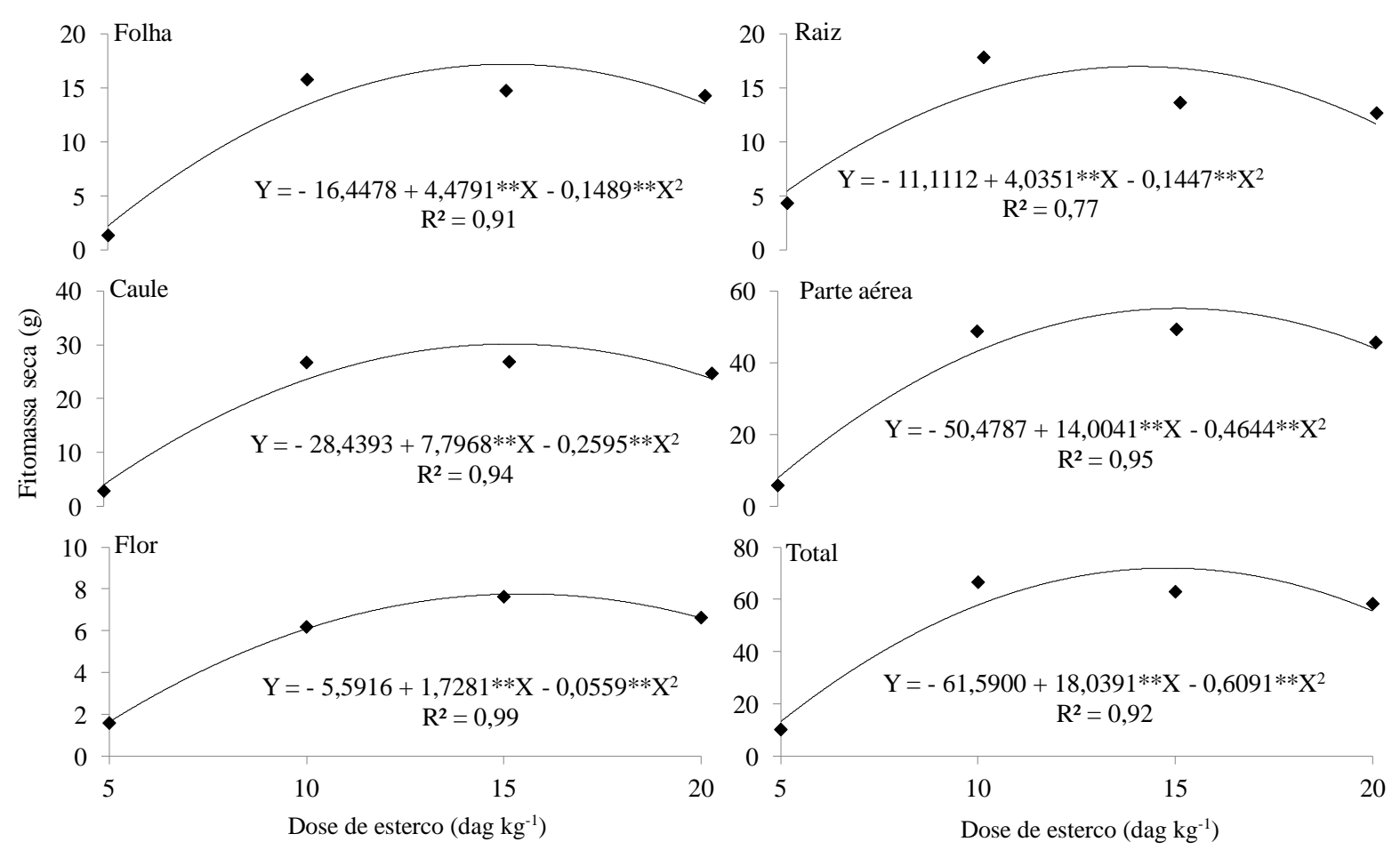

Figura 4 - Fitomassa seca das folhas, caule, flor, raiz, parte aérea e total das plantas de girassol ornamental (cv. 'Sol Noturno') na época de colheita, em função das doses de esterco. Dry mass of leaves, stem, root, aerial part, and the whole plant of ornamental sunflower (cv. 'Sol Noturno') plants at harvest time as influenced by bovine manure doses.

Para o teor de $\mathrm{Mg}^{2+}$ no solo, também, houve efeito significativo dos fatores tipo de água e doses de esterco bovino e da interação entre estes (Tabela 4). Deve-se ressaltar que a concentração de $\mathrm{Mg}^{2+}$ na água residuária foi aproximadamente 3 vezes maior que na água de abastecimento utilizada na irrigação do girassol (Tabela 2). Entretanto, o acúmulo de $\mathrm{Mg}^{2+}$ no solo irrigado com água de abastecimento foi de $64,2 \%$ (7,03 $\left.\mathrm{mmol}_{\mathrm{c}} \mathrm{L}^{-1}\right)$ maior que no solo irrigado com água residuária.

Este resultado deve-se, possivelmente, à dispersividade do $\mathrm{Mg}^{+2}$ quando encontrado em solução no solo e, ainda, ao fato de a água de abastecimento liberar maior quantidade de $\mathrm{Mg}^{2+}$, principalmente quando interage com as doses de 10 e $15 \mathrm{dag} \mathrm{kg}^{-1}$ de esterco bovino, já que a presença de $\mathrm{Mg}^{2+}$ no solo pode indicar um potencial para o crescimento radicular de algumas plantas, como constatou Prado \& Natale (2004).

Com relação aos teores de $\mathrm{Mg}^{2+}$ em função das doses de esterco aplicadas nos solos irrigados com águas residuária e de abastecimento, verifica-se que a irrigação com água de abastecimento provocou acréscimo no teor de $\mathrm{Mg}^{2+}$ até a dose de 13,10 dag $\mathrm{kg}^{-1}$ (efeito quadrático), enquanto com o uso de água residuária na irrigação, há aumento linear no teor de $\mathrm{Mg}^{2+}$ no solo, sendo registrada a taxa de $0,651 \mathrm{mmol}_{\mathrm{c}} \mathrm{L}^{-1}$ de $\mathrm{Mg}^{2+}$ para cada incremento unitário na dose de esterco (Figura 5B).

No caso do teor de potássio $\left(\mathrm{K}^{+}\right)$no solo, houve efeito significativo apenas das doses de esterco bovino (Tabela 4), sendo que o acúmulo máximo de $\mathrm{K}^{+}$no extrato de saturação do solo foi obtido na dose de esterco de 15,06\% (Figura 5C).

Araújo et al. (2007) afirmaram que o uso de esterco bovino de boa qualidade é suficiente para suprir a necessidade das plantas por macronutrientes e que 0 potássio é o elemento cujos teores atingem maiores valores no solo, pelo uso contínuo, o que é confirmado por Raij et al. (1985), além de propiciar melhores condições físicas ao solo.

De forma semelhante ao ocorrido com o $\mathrm{K}^{+}, \mathrm{O}$ teor de sódio $\left(\mathrm{Na}^{+}\right)$no solo foi significativamente influenciado apenas para o fator dose de esterco (Tabela 4). De acordo com a equação de regressão, a concentração de $\mathrm{Na}$ no solo aumenta 6; 7 e 4 vezes para as doses de 10; 15 e $20 \mathrm{dag} \mathrm{kg}^{-1}$, respectivamente, quando se compara com a dose de esterco de 5 dag $\mathrm{kg}^{-1}$ e que o acúmulo máximo de $\mathrm{Na}^{+}$no extrato do solo dá-se numa dose estimada de 13,74 dag $\mathrm{kg}^{-1}$, e após esta dose ocorre decréscimo (Figura 5D).

Mediante o exposto, o aumento da concentração de $\mathrm{Na}^{+}$no solo com a aplicação das doses de 10 e 15 dag 
$\mathrm{kg}^{-1}$ de esterco bovino não se considera benéfico, dado que o acúmulo de $\mathrm{Na}^{+}$no solo tende a potencializar $\mathrm{o}$ processo a sodificação do solo (Munns, 2002).

Os fatores doses de esterco, tipo de água e

Tabela 4 - Resumo da análise de variância para avaliações de cálcio $\left(\mathrm{Ca}^{+2}\right)$, magnésio $\left(\mathrm{Mg}^{+2}\right)$, potássio $\left(\mathrm{K}^{+}\right)$e sódio $\left(\mathrm{Na}^{+}\right)$no extrato de saturação, em solo cultivado com girassol ornamental (cv. 'Sol Noturno') irrigado com água residuária e adubado com esterco bovino. Results of the analysis of variance of data of levels of calcium (Ca), magnesium (Mg), potassium (K), and sodium ( $\mathrm{Na}$ ) in the saturation extract of a soil cultivated with ornamental sunflower (cv. 'Sol Noturno') irrigated with residual water and fertilized with bovine manure.

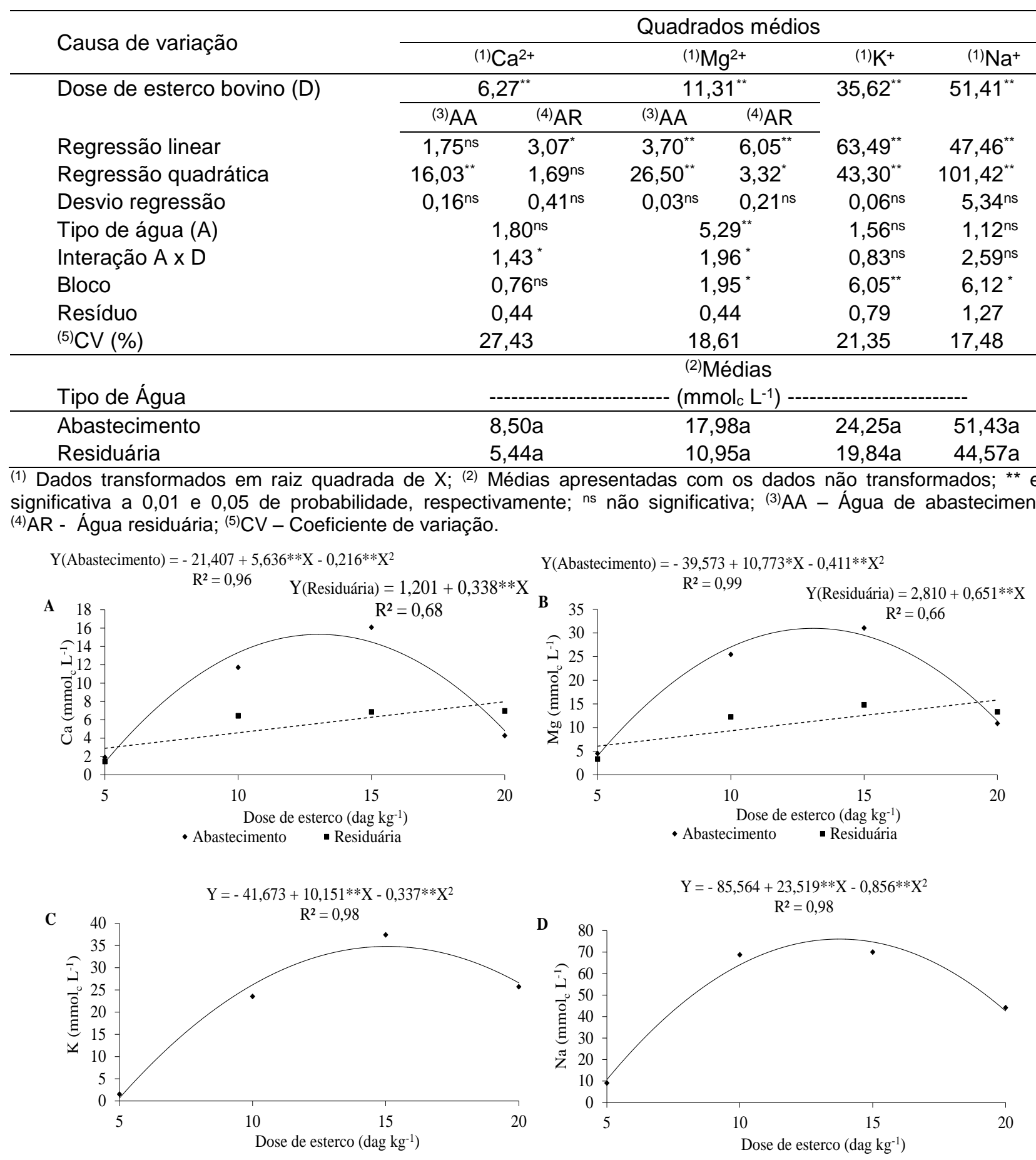

Figura 5 - Teores de cálcio (A), magnésio (B) no extrato de saturação do solo, em função das doses de esterco para as águas residuária e de abastecimento; e potássio $(C)$ e sódio $(D)$ em função das doses de esterco. ${ }^{* *}$ e * significativa a 0,01 e 0,05 de probabilidade, respectivamente. Calcium (A) and magnesium (B) levels in the saturation extract of the soil as influenced by doses of bovine manure and residual and public supply water and potassium (C) and sodium (D) as influenced by bovine manure doses. 
Os teores de $\mathrm{Cl}$ foram superiores nos solos irrigados com água de abastecimento em relação aos irrigados com água residuária, ou seja, a irrigação com água residuária aumentou o teor de cloreto no solo, na ordem de 1,5 vez (Tabela 5).

Não houve efeito significativo do fator tipo de água sobre o teor de bicarbonato $\left(\mathrm{HCO}_{3}^{-}\right)$e a relação de adsorção de sódio (RAS); porém, o uso contínuo de água residuária em irrigações de ciclos sucessivos pode sodificar o solo, posto que a presença de $\mathrm{HCO}_{3}{ }^{-}$ precipita cálcio e magnésio, aumentando a concentração relativa de sódio no solo e os riscos de sodificação. Medeiros et al. (2003) ressaltam que a presença deste íon deve ser considerada de forma efetiva para este processo de sodicidade, a depender das concentrações.

Tabela 5 - Resumo da análise de variância para as variáveis cloreto $\left(\mathrm{Cl}^{-}\right)$, bicarbonato $\left(\mathrm{HCO}_{3}^{-}\right)$, relação de adsorção de sódio (RAS), $\mathrm{pH}_{\mathrm{ps}}$ e condutividade elétrica $\left(\mathrm{CE}_{\mathrm{es}}\right)$ do extrato de saturação, em solo cultivado com girassol ornamental (cv. 'Sol Noturno') irrigado com água residuária e adubado com esterco bovino. Results of the analysis of variance of data of levels of chloride $(\mathrm{Cl})$, bicarbonate $\left(\mathrm{HCO}_{3}\right)$, sodium adsorption relation (RAS), $\mathrm{pH}_{p s}$ and electrical conductivity $\left(C E_{e s}\right)$ in the saturation extract of a soil cultivated with ornamental sunflower (cv. 'Sol Noturno') irrigated with residual water and fertilized with bovine manure.

\begin{tabular}{|c|c|c|c|c|c|c|}
\hline \multirow{2}{*}{ Causa de Variação } & \multicolumn{6}{|c|}{ Quadrados médios } \\
\hline & \multicolumn{2}{|c|}{ (1) $\mathrm{Cl}$} & (1) $\mathrm{HCO}_{3}$ & (2) RAS & ${ }^{(2)} \mathrm{pH}_{\mathrm{ps}}$ & (1) $\mathrm{CE}_{\mathrm{es}}$ \\
\hline \multirow[t]{2}{*}{ Dose de esterco bovino (D) } & \multicolumn{2}{|c|}{$59,84^{* *}$} & \multirow{2}{*}{$2,11^{\star *}$} & \multirow{2}{*}{$312,07^{\star \star}$} & $7,49^{\star *}$ & $9,63^{* *}$ \\
\hline & ${ }^{(3)} \mathrm{AA}$ & (4)AR & & & - & - \\
\hline Regressão linear & $19,29^{* *}$ & $25,35^{* *}$ & $5,69^{* *}$ & $284,39^{* \star}$ & - & - \\
\hline Regressão quadrática & $121,69^{\star \star}$ & $24,29^{* *}$ & $0,43^{\text {ns }}$ & $567,55^{\star \star}$ & - & - \\
\hline Desvio regressão & $2,21^{\text {ns }}$ & $5,97^{\mathrm{ns}}$ & $0,21^{\text {ns }}$ & $84,28^{*}$ & - & - \\
\hline Tipo de água $(A)$ & \multicolumn{2}{|c|}{$9,58^{*}$} & $0,42^{\text {ns }}$ & $16,54^{\mathrm{ns}}$ & $1,90 * *$ & $0,52^{\text {ns }}$ \\
\hline Interação A x D & \multicolumn{2}{|c|}{$6,43^{\star *}$} & $0,16^{\mathrm{ns}}$ & $0,80^{\text {ns }}$ & $0,05^{\mathrm{ns}}$ & $0,59^{n s}$ \\
\hline Bloco & \multicolumn{2}{|c|}{$9,17^{*}$} & $0,18^{\text {ns }}$ & $47,75^{*}$ & $0,97^{* *}$ & $1,40^{* *}$ \\
\hline Resíduo & \multicolumn{2}{|c|}{2,18} & 0,14 & 14,82 & 0,09 & 0,22 \\
\hline (5) CV (\%) & \multicolumn{2}{|c|}{20,55} & 16,50 & 27,30 & 5,37 & 16,98 \\
\hline
\end{tabular}

${ }^{* \star} e^{*}$ significativa a 0,01 e 0,05 de probabilidade, respectivamente; ${ }^{n s}$ não significativa; (1) Dados transformados em Raiz de X; (2) Médias apresentadas com os dados não transformados; ${ }^{(3)} \mathrm{AA}$ - Água de abastecimento; ${ }^{(4)} \mathrm{AR}$ - Água residuária; ${ }^{(5)} \mathrm{CV}$ - Coeficiente de variação.

Analisando a equação de regressão do desdobramento das doses de esterco dentro de cada tipo de água, verifica-se que, com uso de água de abastecimento na irrigação, o teor médio de $\mathrm{Cl}$ no solo é 6,87 vezes maior na dose de $15 \mathrm{dag} \mathrm{kg}^{-1} \mathrm{em}$ relação à dose de 5 dag $\mathrm{kg}^{-1}$, sendo o teor máximo de $\mathrm{Cl}^{-}$ obtido com a dose de 13,05 dag $\mathrm{kg}^{-1}$, sendo 7,86 vezes maior que a quantidade da dose de 5 dag $\mathrm{kg}^{-1}$ de esterco (Figura 6A). A concentração média de cloreto em solo irrigado com água de abastecimento, com dose de 10 e $15 \mathrm{dag} \mathrm{kg}^{-1}$ foi 1,67 e 1,69 vezes maior, respectivamente, do que nos solos irrigados com água residuária.

Pela equação de regressão obtida para a concentração de $\mathrm{HCO}_{3}{ }^{-}$em função das doses de esterco (Figura 6B), estima-se que as doses de 10; 15 e $20 \mathrm{dag} \mathrm{kg}^{-1}$ de esterco concentraram 1,60;2,21 e 2,81 vezes maior $\mathrm{HCO}_{3}{ }^{-}$que a dose de 5 dag $\mathrm{kg}^{-1}$, respectivamente, ou seja, à medida que aumenta 5 dag $\mathrm{kg}^{-1}$ de esterco na dose ocorre acréscimo linear na concentração de $\mathrm{HCO}_{3}$ - de $60,45 \%$, indica que seu uso, em longo prazo, aumenta os riscos com problemas de infiltração de água no solo pelo efeito indireto de $\mathrm{HCO}_{3}$ - sobre a estrutura do solo.

Com o aumento da RAS, a contribuição via matéria orgânica é diminuída, devido à redução da população microbiana, a qual é responsável pela mineralização da matéria orgânica, que por sua vez libera os nutrientes para a solução do solo. Este fato é de suma importância no contexto trazido com esta pesquisa, posto que se estudou o uso de doses de adubo orgânico que, de acordo com a equação de regressão, a maior RAS foi estimada com dose de $14,12 \mathrm{dag} \mathrm{kg}^{-1}$ de esterco, indicando que foi 3,37; 1,17 e 1,41 vezes maior que a RAS obtida sob dose de 5 ; 10 e 20 dag kg$^{-1}$, respectivamente (Figura 6C).

É importante ressaltar que o final do ciclo é o momento considerado mais importante em termos de avaliação na alteração dos atributos do solo, já que se deve considerar a situação do solo para a tomada de decisão sobre o manejo a ser escolhido para o próximo ciclo ou plantio. Assim, a contribuição da dose de $10 \mathrm{dag} \mathrm{kg}^{-1}$ foi a mais destacada em termos de valores de RAS, encontrando-se bem acima da curva, do qual este ponto é distante em 2,72 (mmol L-1 $)^{0,5}$ do ponto em que se encontra em seguida (15 dag $\mathrm{kg}^{-1}$ ) (Figura 6C). Isto significa dizer que, fazendo uso da dose de 10 dag $\mathrm{kg}^{-1}$, aumentam-se os riscos de impactos ambientais negativos ao solo, uma vez pode ocorrer sodificação do solo. 


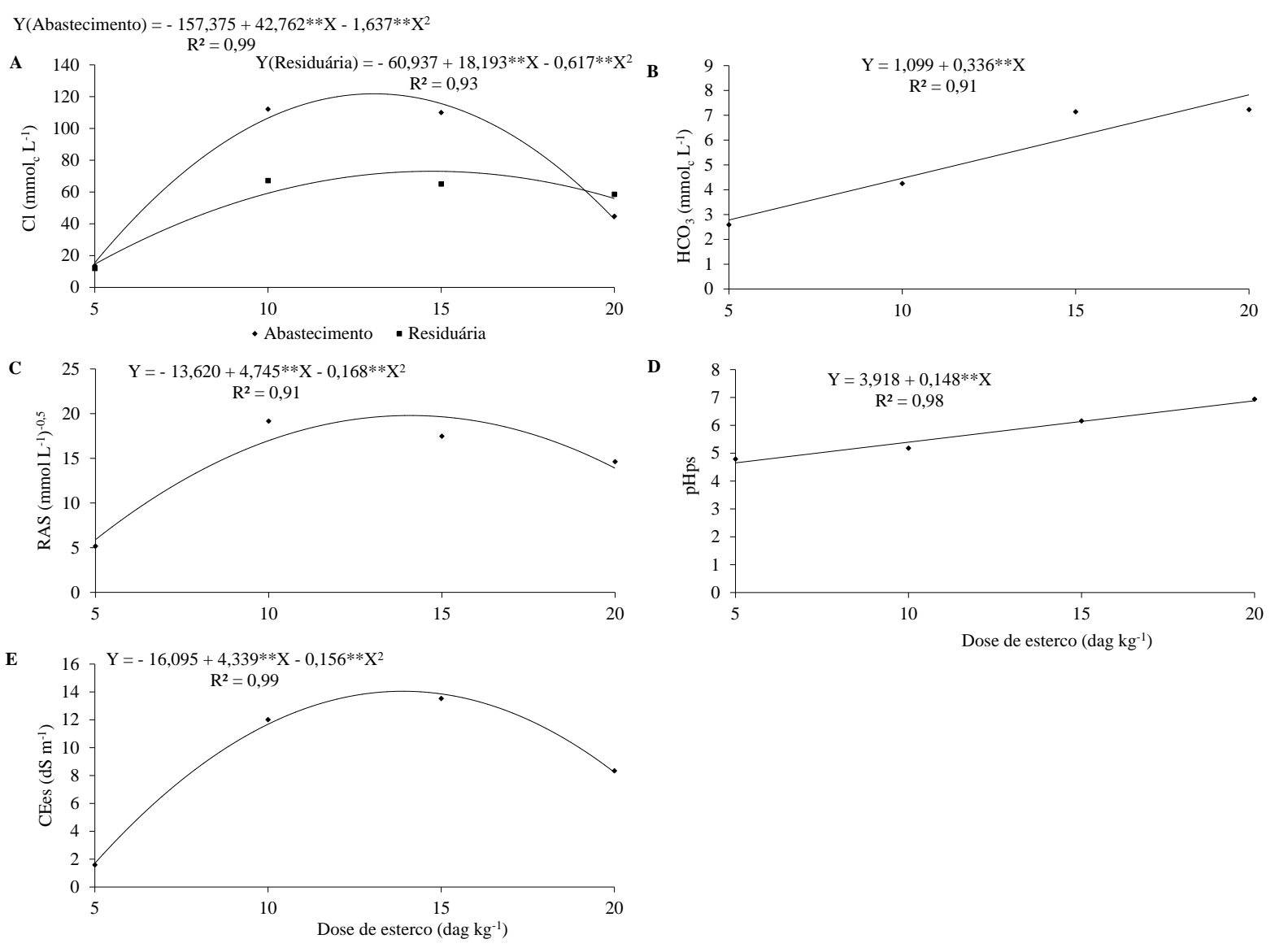

Figura 6 - Teores de Cloreto no solo $(\mathrm{Cl})(\mathrm{A})$, bicarbonato $\left(\mathrm{HCO}_{3}^{-}\right)(\mathrm{B})$, Relação de Adsorção de Sódio (RAS) (C), $\mathrm{pH}_{\mathrm{ps}}(\mathrm{D})$ e Condutividade elétrica (CEes) (E) no extrato de saturação do solo, em função das doses de esterco aplicadas. ${ }^{* *} \mathrm{e}$ * significativa a 0,01 e 0,05 de probabilidade, respectivamente. Soil chloride $(\mathrm{Cl})(\mathrm{A})$, bicarbonate $\left(\mathrm{HCO}_{3}{ }^{-}\right)(B)$, sodium adsorption relation $(\mathrm{RAS})(\mathrm{C}), \mathrm{pH}_{p s}(\mathrm{D})$, and electrical conductivity $(C E e s)(E)$ in the saturation extract of a soil as influenced by the applied manure doses, respectively.

Apesar de a RAS da água residuária tratada utilizada ser, em média, superior aproximadamente 3 vezes à encontrada na água de abastecimento fornecida durante o período experimental, não se obteve diferença na RAS entre os tipos de água. Porém variações nos componentes químicos na água residuária devem ser consideradas, tendo em vista que as descargas de esgoto doméstico variam diariamente, e a presença e ausência de chuvas diluem ou concentram os íons contidos nesta água, por razão de uma RAS maior neste experimento.

Com relação ao $\mathrm{pH}_{\mathrm{ps}}$ e à condutividade elétrica ( $\left.\mathrm{CE}_{\mathrm{es}}\right)$ do extrato de saturação do solo, não houve efeito significativo $(p>0,01)$ na interação dos fatores estudados, porém para o fator doses de esterco bovino ocorreu efeito significativo para as duas variáveis e, no fator tipo de água, houve apenas diferença significativa para o $\mathrm{pH}_{\mathrm{ps}}$ (Tabela 5).

A irrigação com água residuária proporcionou um $\mathrm{pH} 7,99 \%$ maior que o $\mathrm{pH}$ do solo irrigado com água de abastecimento e, segundo a equação de regressão (Figura 6D), este aumentou linearmente com o acréscimo da dose de esterco, apresentando um incremento de $15,89 \%$ para cada intervalo de dose estudado (5 dag kg-1) ou um aumento no $\mathrm{pH}$ de $3,18 \%$ para cada aumento unitário da dose de esterco.

$\mathrm{O} \mathrm{pH}$ da pasta de saturação manifestou-se de modo que, entre as doses estudadas, a que influenciou para a obtenção de $\mathrm{pH}$ mais próximo à neutralidade, estimado em 6,88 , foi a da dose de $20 \mathrm{dag} \mathrm{kg}^{-1}$ de esterco, já a que proporcionou valores de $\mathrm{pH}$ mais ácidos, dentre as estudadas, foi a dose de

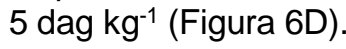

Este aumento do $\mathrm{pH}$ diretamente proporcional à quantidade de esterco bovino aplicado ao solo, não concorda com Guimarães et al. (2009), ao afirmar que a aplicação de adubos orgânicos em solos, além do efeito direto no suprimento de nutrientes, para as plantas, contribui para a permeabilidade e infiltração de água, favorece a microbiota natural do solo, melhora as condições físicas do solo e contribui para baixar os teores de Al trocável, causados pelo aumento dos valores de $\mathrm{pH}$ neste experimento, com aumento da dose.

Com relação à $\mathrm{CE}_{\text {es }}$ do solo, houve efeito quadrático crescente em função das doses de esterco bovino (Figura $6 \mathrm{E}$ ), com ponto de máximo na dose de 13,91 dag kg-1 (14,08 dS m-1). A CEes não variou esta- 
tisticamente com os tipos de água utilizada para a irrigação. Pessoa et al. (2010) e Gonçalves et al. (2011), estudando alterações químicas em Neossolos do semiárido de Pernambuco, não observaram alterações significativas em função da água de irrigação.

O uso excessivo do esterco bovino no solo pode aumentar a $\mathrm{CE}_{\mathrm{es}}$, a razão de adsorção de sódio devido à precipitação de $\mathrm{Ca}$ causada pelo excesso de $\mathrm{HCO}_{3}$, além de toxicidade pelo excesso de cloreto (Araújo et al., 2013).

\section{Conclusões}

A adubação nas doses entre 10 e 15 dag $\mathrm{kg}^{-1}$ de esterco bovino é a mais indicada para se atingir o crescimento máximo do girassol ornamenta (cv. Sol Noturno) cultivado em vasosl.

Há efeito quadrático crescente sobre teores de $\mathrm{Ca}^{2+}$ e $\mathrm{Mg}^{2+}$ no solo em função das doses de esterco bovino para os solos irrigados com água de abastecimento e efeito linear crescente nos solos irrigados com água residuária.

Os teores de $\mathrm{K}^{+}$e $\mathrm{Na}^{+}$no solo aumentaram com o incremento das doses de esterco bovino, respectivamente, até às doses de 15,06 e 13,74 dag $\mathrm{kg}^{-1}$, independentemente do tipo de água de irrigação.

O teor de $\mathrm{Cl}^{-}$no solo, em função das doses de esterco bovino responde de forma quadrática para os dois tipos de água de irrigação, sendo a com a maior taxa de variação para água de abastecimento.

O uso excessivo do esterco bovino no solo aumenta os riscos de salinização e sodificação e a toxicidade por excesso de cloreto dos solos cultivados com girassol, independentemente do tipo de água de irrigação.

\section{Referências}

Alves WWA, Azevedo CAV, Dantas Neto J, Sousa JT, Lima VLA (2009) Águas residuárias e nitrogênio: efeito na cultura do algodão marrom. Revista Verde de Agroecologia e Desenvolvimento Sustentável 4(1): 16-23.

Araújo ASF, Silva MDM, Leite LFC, Araújo FF, Dias NS (2013) Soil pH, electrical conductivity and organic matter after three years of consecutive applications of composted tannery sludge. African Journal of Agricultural Research 8(5):1204-1208. .

Araújo EM, Oliveira AP, Cavalcante LF, Pereira WE, Brito NM, Neves, CLM, Silva, EE (2007) Produção de pimentão adubado com esterco bovino e biofertilizante. Revista Brasileira de Engenharia Agrícola e Ambiental 11(5):466-470.

Ayers RS, Westcot DW (1999) A qualidade da água na agricultura. Tradução de Gheyi, HR, Medeiros JF, Damasceno FAV. UFPB, 218p. (Estudos FAO. Irrigação e Drenagem, 29).
Costa FX, Beltrão NEM, Lima, VLA, Azevedo CAV, Soares FAL, Alva IDM (2009) Efeitos residuais da aplicação de biossólidos e da irrigação com água residuária no crescimento do milho. Revista Brasileira de Engenharia Agrícola e Ambiental13(6):687-693.

Duarte AS, Airoldi RPS, Folegatti MV, Botrel TA, Soares TM. (2008) Efeitos da aplicação de efluente tratado no solo: pH, matéria orgânica, fósforo e potássio. Revista Brasileira de Engenharia Agrícola e Ambiental 12(3):302-310.

Embrapa - Empresa Brasileira de Pesquisa Agropecuária (1997). Centro Nacional de Pesquisa de Solos. Manual e métodos de análise de solo. 2.ed. Rio de Janeiro. 212p.

Fonseca AF, Melfi AJ, Montes CR (2005) Maize growth and changes in soil fertility after irrigation with treated sewage effluent. I. Plant dry matter yield and soil nitrogen and phosphorus availability. Communications in Soil Science and Plant Analysis. 36(13):1965-1981.

Galvão SRS, Salcedo IH, Oliveira FF (2008) Acumulação de nutrientes em solos arenosos adubados com esterco bovino. Pesquisa Agropecuária Brasileira 43(1):99-105.

Gonçalves IVC, Freire MBGS, Santos MA, Santos ER, Freire FJ (2011) Alterações químicas de um Neossolo Flúvico irrigado com águas salinas. Revista Ciência Agronômica 42(3):589-596.

Guimarães AS, Santos NR, Beltrão NEM (2009) Fontes e doses crescentes de adubos orgânicos e mineral no crescimento inicial de pinhão manso. Mens Agitat.4(1):17-22.

Medeiros JF de, Lisboa RA, Oliveira M, Silva Júnior MJ, Alves LP (2003) Caracterização das águas subterrâneas usadas para irrigação na área produtora de melão da Chapada do Apodi. Revista Brasileira de Engenharia Agrícola e Ambiental 7(3):469-472.

Menezes RSC, Salcedo IH (2007) Mineralização de N após incorporação de adubos orgânicos em um Neossolo Regolítico cultivado com milho. Revista Brasileira de Engenharia Agrícola e Ambiental 11(4):361-367.

Munns R (2002) Comparative physiology of salt and water stress. Plant Cell Environment.25(1): 239-250.

Pessoa LGM, Oliveira EEM, Freire MBGS, Freire FJ, Miranda MA, Santos RL (2010) Composição química e salinidade do lixiviado em dois solos cultivados com cebola irrigada com água salina. Revista Brasileira de Ciências Agrárias.5(3):406-412. 
Prado RM, Natale W (2004) Calagem na nutrição de cálcio e no desenvolvimento do sistema radicular da goiabeira. Pesquisa Agropecuária Brasileira. 39(12):1007-1012.

Raij B van, Silva MN, Bataglia OC, Quagio JÁ (1985) Recomendações de adubação e calagem para 0 Estado de São Paulo. Campinas. 170p.

Rodrigues LN, Nery AR, Fernandes PD, Beltrão NEM, (2009) Aplicação de água residuária de esgoto doméstico e seus impactos sobre a fertilidade do solo. Revista de Biologia e Ciências da Terra 9(1):56-67.
Sampaio PRF, Almeida JPN, Mota AF, Costa LR, Gurgel MT (2011) Utilização de águas residuárias na germinação e desenvolvimento inicial de mudas de meloeiro 'Amarelo Ouro'. Revista Verde de Agroecologia e Desenvolvimento Sustentável, 6(1):179-187.

Souza RM, Nobre RG, Gheyi HR, Dias NS, Soares FAL (2010) Utilização de água residuária e de adubação orgânica no cultivo do girassol. Revista Caatinga 23(2):125-133 